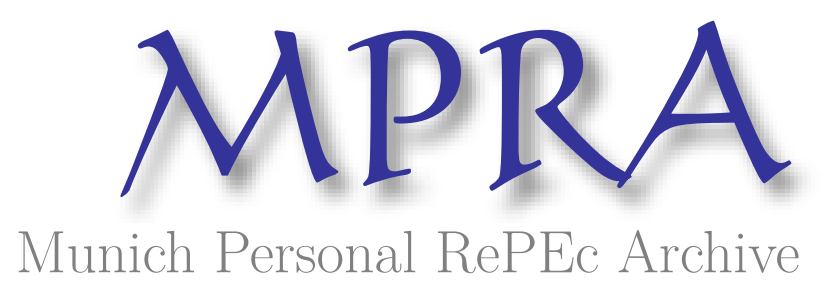

\title{
Longitudinal Poverty and Income Inequality A Comparative Panel Study for The Netherlands, Germany and the UK
}

Muffels, Ruud and Fouarge, Didier and Dekker, Ronald

OSA Institute for Labour Studies

2000

Online at https://mpra.ub.uni-muenchen.de/13298/

MPRA Paper No. 13298, posted 11 Feb 2009 08:46 UTC 


\title{
Longitudinal Poverty AND Income INEQUALITY
}

\author{
A COMPARATIVE PANEL STUDY FOR THE NETHERLANDS, \\ GERMANY AND THE UK
}

Ruud Muffels, Didier Fouarge \& Ronald Dekker

Tilburg Institute for Social Security Research (TISSER), Tilburg University

Corresponding author:

Didier Fouarge, TISSER / OSA

PO Box 90153

5000 LE Tilburg.

The Netherlands

Tel.:++(0)134663001 / 3095

Fax. ++(0)134663349

E-mail: fouarge@kub.nl 
The scientific research programme of the Institute for Labour Studies (OSA) is based on current and planned labour research of the Tilburg University participants CentER (Faculty of Economics and Business Administration), WORC (Faculty of Social and Behavioural Sciences), CentER for Applied Research and Institute for social policy research and consultancy (IVA) and of the labour researchers of Utrecht University.

The OSA working paper series intends to disseminate results of research conducted under the heading of the OSA scientific programme. OSA working papers may include views on policy, but any opinions expressed are those of the author(s) and not those of the Institute.

More information about OSA can be found at our internetsite http://osa.kub.nl

\section{Tilburg University}

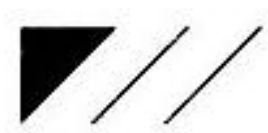




\title{
LONGITUDINAL POVERTY AND INCOME INEQUALITY A COMPARATIVE PANEL STUDY FOR THE NETHERLANDS, GERMANY AND THE UK
}

\author{
Ruud Muffels, Didier Fouarge \& Ronald Dekker*
}

\begin{abstract}
The increasing availability of longitudinal data on income in Europe greatly facilitates the analysis of income and poverty dynamics. In this paper, the results of longitudinal dataanalyses on income and poverty in three European welfare states are reported. Using panel data for Germany, the Netherlands and the UK a variety of longitudinal inequality and poverty measures have been applied to reveal these dynamics. The focus will be on so-called poverty profiles indicating whether people belong to the permanent poor, the transient poor, the recurrent poor or the never poor. Multinomial regression models are estimated that aim to explain the likelihood of belonging to each of the poverty profiles over time and on the events that trigger the belonging to the poverty profiles over time.

Our results show that there is a great deal of economic mobility in and out of poverty over time. Most of the poor are only poor for a short period of time but, nevertheless, a substantial part of the population is found to be persistent poor. This is particularly the case in the UK. In matured welfare states, income mobility and persistency of poverty are co-occurring. Our analysis of poverty profiles shows that especially labour market events trigger the belonging to the persistent, the recurrent or the transient poor.
\end{abstract}

Keywords: income dynamics, poverty, comparative analysis, welfare states, panel data, multinomial regression

JEL Classification: D31, D63, C23, I32

ACKNOWLEDGEMENTS
The research was carried out as part of the European Panel Analysis Group (EPAG;
http://www.iser.essex.ac.uk/epag). The authors gratefully acknowledge the funding by the European
Commission in the framework of the TSER program: The PanEL Project; European Panel Analysis
(SOE2.CT96.3023).
The data for the Netherlands used in this paper are from the Dutch Socio-economic Panel survey and were
made available by Statistics Netherlands. The German data are from the German Socio-economic Panel and
were made available by the Deutsche Institut für Wirtschaftsforschung. The data for the UK were made
available through the ESRC Data Archive. The data were originally collected by the ESRC Research Centre
on Micro-social Change at the University of ESSEX. Neither the original collectors of the data nor the Data
Archive, in the case of the UK data, bear any responsibility for the analyses or interpretations presented here.




\section{NON TECHNICAL SUMMARY}

The bulk of international comparisons of poverty and inequality only provide snapshot information based on cross-sectional data. Such studies tend to overestimate the degree of poverty and inequality because they do not account for the dynamics of poverty and income. In this paper we apply some longitudinal measures of poverty and inequality on the existing longer running panel data sets for Germany, the Netherlands and the UK. The results are reported from two perspectives. First, across welfare states, the question addressed is how welfare states perform in terms of income redistribution and (persistent) poverty alleviation. Next, across time, the focus is on a comparison of the short-, medium- and longer term results in terms of poverty reduction.

Across welfare states, it is clear that the Dutch and German welfare states do an excellent job in preventing poverty and inequality not only in the short-term but also in the medium- and longer term without distorting efficiency to considerable extents. The UK system produces higher levels of poverty, whether transient, recurrent or persistent. Over a five-year period, the UK has $40 \%$ more recurrent and persistent poverty than Germany or the Netherlands. Comparing the Dutch and German welfare states it turns out that they are performing equally well in preventing welfare state dependency in the medium- and longer term. Comparison of pre- and postgovernment poverty rates makes clear that the market does a much poorer job than the governments in preventing poverty in the short-, medium- and long-term. Nevertheless the UK has to accept fairly high levels of recurrent and persistent poverty among particular group such as the single parent families and the unemployed.

Across time, the Dutch and German welfare systems turn out to be very successful in reducing inequality and poverty, particularly in the longer term. But also the UK welfare system is successful at reducing poverty but more so in the longer run than in the short run. For all the countries, the UK included, it does not seem that the market can prevent the existence of long-term poverty. On the contrary, it is through government intervention that poverty is successfully tackled. Longitudinal measures of poverty give a better, deeper view on poverty and tell a different story than the usual snapshots. On the one hand, they show that poverty is not reduced to be a problem for a small group of low-income people in society. It appears a widespread social phenomenon because in the longer run many more people are prone to poverty than in the short run. On the other hand, it makes clear that much of poverty in the longer run is only temporary. Many people have a single experience of poverty and do not need much help to escape from poverty and to keep out of it. In general there is much more economic mobility than the annual snapshots suggest even at 
these low levels of income. There is another story told by these figures which is that, apart from the high levels of economic mobility among the poor, there is much persistent poverty. Income mobility and poverty persistence go hand in hand even in growing economies and matured and developed welfare states. Our analyses suggest that both household formation and labour market events are responsible for the mobility into and out of poverty. Where the transient and recurrent poor share many characteristics of the persistent poor, the likelihood of being part of a separated household, having a low education level or low earnings is in all instances larger with the persistent poor. The persistent poor share the experience of divorce and family breaks and the occurrence of significant changes in the labour market status of household members due to work loss or work gain. They have a lower human capital value and they lack the resources in terms of skills, education and working experience that can be exchanged on the market for jobs. 


\section{INTRODUCTION AND OUTLINE}

The focus in this paper is on poverty dynamics using income as the yardstick for welfare comparisons across population groups. Previous international comparisons of poverty and inequality have been generally based on annual cross-sectional data, of which the most well known and comprehensive is the Luxembourg Income Study (Mitchell, 1991, Smeeding et. al., 1993, Atkinson, Rainwater and Smeeding, 1995). Comparative studies of income and poverty dynamics are just beginning to appear because there are not many countries with longer running panels that permit to do these sorts of analyses. For three countries there are panel data running for more than ten consecutive years: the US, Germany and the Netherlands. Given that we want to focus on a comparison of European welfare states we will not use the US data for presentation. A comparison with the US can be found in earlier work on the issue (Headey, Goodin, Muffels \& Dirven, 1997, 2000). Ten years seems sufficiently long to assume that the outcomes reflect the longterm. In the UK, there is a panel running for five consecutive years which will be used in for comparison. The five years of data for Germany, the Netherlands and the UK are supposed to reflect the medium-term. Hence, in the paper, a comparison is made between the short (annual) and medium-term (five years) results for three countries and the longterm (ten years) results for two.

The first section of this paper deals with the definition of poverty and social exclusion in a dynamic perspective. In Section 2 longitudinal definitions of poverty are explained. Then the notion of longitudinal poverty profiles is developed according to which a distinction is introduced between transient, permanent and recurrent poverty. Since panel data are used for the UK, Germany and the Netherlands, it is feasible to compare the outcomes for three unique but clearly distinct types of welfare states. The data sets used in this paper are briefly described in Section 3. In Section 4, comparative evidence is presented on the longitudinal inequality and poverty measures. Apart from statistical measures applied on the individual level a brief discussion is opened on a model-based measure of longitudinal poverty. Then, in Section 6, the focus is on the events that trigger the various sorts of poverty profiles over time. Some conclusions about the substantive outcomes and future research are drawn in the last section of the paper.

\section{LONGITUDINAL DEFINITIONS OF POVERTY}

\subsection{The concept of poverty}

It goes without saying that since our research deals with poverty in affluent developed societies the term poverty is primarily used in its relative meaning. This does not necessarily imply that absolute poverty is fully absent in these societies -e.g. the 
homeless and illegal migrants- but that the incidence of absolute poverty is clearly much lower compared to the incidence of relative poverty. As a yardstick for relative poverty we use a measure of the income distribution being the half median equivalent income, as adopted by the European Commission in much of their research on the issue. The equivalence scale assigned to this poverty line is the so-called modified OECD-scale which assigns a weight of 1 to a single person, 0.5 to every additional person aged 14 years or more and 0.3 to every person aged less than 14 .

In earlier work (Dirven, Fouarge, Muffels, 1998) a classification of poverty definitions is used based on two dimensions. The first dimension starts from the distinction between direct and indirect definitions of poverty which was developed by Ringen some ten years ago (Ringen, 1988). Before him, Sen (1979) already made a distinction between the direct method and the income method and Atkinson (1987) between the right to a minimum level of resources and the attainment of a minimum standard of living. In all these approaches income -or resources- definitions are distinguished from definitions in terms of consumption patterns and standard of living. The so-called indirect method has been used by Ringen to refer to income definitions, and the term direct to consumption, deprivation or budget definitions (see also Muffels, 1993). Both types of definitions may also be distinguished according to their mono- or multidimensional (inclusive) character. The indirect method considers poverty as a state of low welfare or insufficient income while the second sees poverty as a multifaceted or multidimensional deprivation concept where material wellbeing is part of an inclusive list of resources and amenities. In this paper we limit ourselves to the indirect method using income as a yardstick for welfare instead of consumption or deprivation. Another possibility would be to pay attention to the direct method and, in particular, the comparison of the income and consumption or deprivation method. For an extensive treatment of this issue compare Callan, Nolan \& Whelan (1996).

The second dimension of our classification points to the distinction between static and dynamic definitions of poverty. Terms like income poverty or relative deprivation are generally conceived in their static meaning, as instantaneous notions of low income or relative deprivation where the person or household is in at a certain point in time. In the conventional approach there is little consideration for the longitudinal aspect of poverty. In a dynamic approach, what matters is how poverty statuses evolve over time: whether people are able to escape transitory instances of poverty conditional on the length of stay in poverty, how stable or unstable income positions are over time and whether poverty is a recurrent phenomenon or not. In a dynamic approach the interest goes therefore to longitudinal patterns of poverty and deprivation, and to the factors which determine the process of impoverishment and exclusion from average living standards. This leads to a matrix for the classification of poverty definitions as presented in Table 1. 
Table 1: Conceptualisation of poverty definitions

\begin{tabular}{lll}
\hline Poverty definitions & $\begin{array}{l}\text { Static } \\
\text { (situation or state at one point } \\
\text { in time) }\end{array}$ & $\begin{array}{l}\text { Dynamic } \\
\text { (process or evolution over } \\
\text { time) }\end{array}$ \\
\hline $\begin{array}{l}\text { Indirect } \\
\text { (income, command over } \\
\text { resources) }\end{array}$ & $\begin{array}{l}\text { Income poverty, } \\
\text { income deprivation } \\
\text { Direct } \\
\text { (consumption budget, }\end{array}$ & Relative deprivation \\
living standard) & $\longrightarrow \begin{array}{l}\text { Longitudinal poverty, } \\
\text { impoverishment }\end{array}$ \\
\hline
\end{tabular}

Source: Berghman, 1995

The use of terms such as impoverishment, referring to low income, and social exclusion, referring to low consumption, mirror the longitudinal approach to poverty and the focus on poverty dynamics. In the dynamic approach the attention goes to processes or the sequence of life events leading people to enter or to escape from poverty. The longitudinal concept of poverty adds the time dimension to the static poverty concept, which makes it fundamentally different. As Walker argued it is not just another dimension: "it is the medium within which poverty occurs and shapes the experience of being poor" (Walker, 1994: 11).

The time nature itself should be part of the definition since the experience of short-term and long-term poverty, the welfare assigned to the poor's standard of living and the strategies they adopt to cope with poverty and exclusion at the micro-level are quite distinct. In the short run people may be able to make ends meet by drawing on their savings and reduce their expenditures, but for the longer run these strategies are often insufficient to cope with the income shortfall. But apart from the magnitude of the income shortfall -or poverty gap- and the duration -or spell-length- of the shortfall, attention should be paid to the distribution of poverty across the population over time. Particularly, its recurrent nature and therewith the prevalence of poverty in society over time should be subject to the concern of academic researchers.

The distribution of poverty over time depends not only on the number of people in poverty, but also on the income mobility, the duration of poverty spells and the extent of recurrent poverty. The higher income mobility or income volatility is in a certain time period and the shorter the spell-duration, the higher the prevalence of poverty in society, i.e. the proportion of people experiencing poverty at least once during the period. But also, the lower the share of recurrent poverty, the higher prevalence is. However, the prevalence is directly affected by the length of the observation period. Given the extent of 
poverty in society, a longer accounting period causes poverty rates to fall since short-term changes in poverty statuses are evened out in the longer run.

Summarising, it is shown that the time dependent nature of poverty is characterised by four dimensions:

- $\quad$ the length of the observation period;

- $\quad$ the length of the poverty spell;

- $\quad$ the extent of recurrent spells;

- $\quad$ the volatility and stability of poverty statuses over time.

These four dimensions of longitudinal poverty together determine the pattern or profile of poverty for each individual over time. In the paper four types of poverty profiles are distinguished:

- $\quad$ the persistent non-poor (never poor in the accounting period);

- $\quad$ the transient poor (once poor in the accounting period);

- $\quad$ the recurrent poor (more than once poor but never longer than two years);

- $\quad$ the persistent poor (poor for a consecutive period of at least three years).

The measure of persistency of poverty (being poor for at least three consecutive years) is rather arbitrary although from earlier research (Headey et al., 1998) it is known that the likelihood of escaping poverty diminishes rapidly after having resided in poverty for two or more years. Given the longer running panel data, quite distinct poverty profiles can be observed across the population.

\section{Pre- and post-government income}

In assessing income, the objective is actually to measure people's command over resources or the material standard of living people can afford given their income. How income is translated into consumption and material standards of living is confounded by many factors such as the size and composition of the household, the management skills of its members, income pooling within the household or the savings behaviour. It is therefore assumed that the welfare of each household bears a kind of curve linear relationship with the level of cash income. In our approach the conventional wisdom is adopted of complete income pooling within the household, attributing the same household income to every member of the household. Economies of scale are accounted for by adjusting household income for differences in household size and household composition. As mentioned already, the equivalence scale used is the so-called modified OECD-scale which assigns a weight of 1 to a single person, 0.5 to every additional adult and 0.3 to every person below 14 years of age. 
The income definition applied in the paper is after tax disposable household income. This is called post-government income and is equal to the total of gross labour income, asset income and private transfers plus gross social security payments and public income transfers minus direct taxes (income tax plus social security contributions). Income does not include the value of owner occupied housing nor the value of non-cash benefits. Pregovernment income equals post-government income minus net social security payments and public income transfers. Paid taxes and social security contributions are still included in pre-government income. Pre-government income could be conceived as the incomes people would receive in the absence of public benefits. Of course this can be criticised since, obviously, if there were no government, no taxes or social security contributions would have to be paid, economic behaviour and most other forms of behaviour would be very different and would lead to quite different distributive outcomes.

Pre- and post-government income is used to assess the redistribution by government transfers. The redistribution figures therefore only account for the effect of social security transfers and not for the effect of taxes. The impact of government transfers on household income is given by the following general formula (see also Kakwani, 1986):

\section{Governmental $=$ pre-government income - post-government income $\times$ $100 \%$ \\ Redistribution (\%) pre-government income}

The method can easily be applied to assess the redistributive effect of public transfers on inequality and poverty. To assess the impact of government on poverty reduction the procedure is simply to calculate the poverty rate for pre-government incomes, subtract the poverty rate for post-government incomes, divide it by pre-government poverty and multiply it by 100 .

\subsection{E mpirical measures for longitudinal poverty}

It is interesting to compare longitudinal measures of poverty for the three countries with the conventional static measures that are still dominant in the political debate. As static measures the conventional head count ratios are used: the percentage of persons with an income below the poverty line.

Then for each of the four dimensions of longitudinal poverty different kinds of measures are applied. For the length of the observation period, the panels at our disposal give us the opportunity to make a distinction between short-term (one year), medium-term (five years) and long-term (ten years) inequality and poverty. For the short- and medium-term comparisons can be made across the three countries. However, for the long-term we only 
have data for Germany and the Netherlands. Since only annual information on the poverty statuses is available, the length of the poverty spell is defined as the number of years people are living in poor households from time $t$ on given that these people live in non-poor households at time $t$ - 1 . The extent of recurrent poverty is measured by the socalled 'poverty hit-rates' over time or the frequency of poverty experiences during the accounting period.

Two methods to measure the volatility and stability of income positions over time will be used. The first method is the spell approach, derived from survival analyses in biological research (life table analysis). It gives information about the exit or escape rate out of poverty conditional on being in poverty for a certain number of years. Whereas these exit rates give information on the income mobility, the staying probabilities (the reverse of the exit rates) render insight into the stability of income positions over time.

The stability of income positions is also measured by a model-based approach of poverty persistence derived from Duncan \& Rodgers (1991). Persistent poverty is now defined as a situation in which the permanent income is below the poverty line. The idea behind the measure is that people have a rather permanent latent income-to-needs ${ }^{1}$ level from which occasional departures are possible because of temporary income shocks due to (un)employment, disability, illness, overtime work, incidental income flows, etc. The model is not able to identify individuals living in persistent poverty, since it can only provide a population wide estimate of the existence of persistent poverty in society. In a separate paper the model is applied on the data for the three countries but the results are given and shortly commented on in this paper.

${ }^{1}$ For each person, the income-to-needs ratio equals the standardised income divided by the poverty line. 


\section{THE DATA}

The Dutch Socio-economic Panel (SEP) began in 1984 with around 11,000 respondents in 4,000 households, and has been enlarged on various occasions to get (and keep) it at a level of about 5,000 households. All household member aged 16 and over are interviewed. Initially, interviews were carried out twice a year in April and October, but in 1990 it was decided to switch to annual interviews. Previous to 1990 respondents were asked for their net personal income the previous month. These data have been annualised to produce a yearly income. From 1990 onward, however, respondents are asked for their gross income in the previous year. Paid taxes have been estimated and subtracted in order to produce a net yearly income. The income data for the Netherlands then run from 1985 to 1994.

The German data come from the German socio-economic panel (GSOEP). It began in 1984 in West Germany and, after reunification, was extended to cover the whole of Germany in 1990. The initial sample included over 16,000 respondents, with everyone aged 16 and over in sample households being interviewed. Special over-samples of five foreign (guest-worker) communities were included: Italians, Greeks, Yugoslavs, Spanish and Turks. Weights are used to adjust for this and other sample biases. The German Institute for Economic Research and Syracuse University have produced matching files for the German and American panels in which key variables relating to income, labour force experience, taxes and transfers were coded identically to facilitate international comparisons. The 1986 through 1996 waves of the data are used containing retrospective income data for the year previous to interview. This means that income data are available for Germany running from 1985 to 1995. However, no income data are available for East Germans for the waves previous to 1992. When applicable, and unless otherwise mentioned, the data presented here include both the Western and the Eastern samples. De facto, the data for the Eastern sample are excluded from all analysis involving income data from the waves prior to 1992 .

The data set for the UK is the British Household Panel Survey (BHPS) which started in 1991. It has an initial sample of approximately 14,000 persons living in 5,000 households.

Like in the Dutch panel, all household members aged 16 and over are interviewed and no oversampling has taken place of particular population categories. In the BHPS, respondents are asked to report on their gross income. The gross income variables refer to the period of one year back up to August of the current year, the date of interview. Gross incomes have been converted into net incomes, which are supplied in an unofficial supplement to 
the BHPS data (cf. Jarvis and Jenkins, 1998). Hence, gross and net income is available for the UK for the years 1991 through $1995 .^{2}$

Using these data, a longitudinal data file has been constructed for all three countries. This means that a ten-year comparable data set for Germany and the Netherlands is available, with income data for the year 1985 through 1994, and a five-year comparable data set for all three countries, covering the years 1991-1995 (1990-1994 for the Netherlands).

The results presented here are at the individual level. Information at the household has been assigned to each individual in the household. The data are first weighted on a crosssectional basis to make them representative for the population of the particular country. Next, longitudinal results have been weighted with a longitudinal weight in order to correct for possible selective drop out.

\section{SHORT-, MEDIUM- AND LONG-TERM POVERTY AND INCOME INEQUALITY AND THE ROLE OF THE WELFARE STATE}

\subsection{Poverty}

In Table 2 the short-, medium- and long-term poverty figures are given for the Netherlands, Germany and the UK. The data in the table show that pre- and post-government poverty is highest in the UK. Because of the high levels of pre-government poverty in the UK the redistribution by the government in terms of reduction of pre-government poverty is about equally high as it is in the Netherlands and Germany. The high levels of pre-government poverty indicate that in the UK people at the lower tails of the income distribution are very dependent on the income transfer policies of the government to make a decent living. Obviously, the market is unable to provide for decent labour incomes for low-income earners. If the short-term are compared with the long-term results, it is apparent that for all the three countries in the longer run the pre- and post-government poverty rates are lower than in the short run although the pre-government rates are not much lower. Presumably, this is caused by a high level of income volatility or economic mobility, which means that due to the operation of the market situations of income shortfall are, in quite some cases, followed by instances of income surplus. One may presume that the government seems capable of smoothing people's household incomes in the medium term by providing adequate benefits in those instances that in any given year market income falls short of providing a decent minimum income.

\footnotetext{
2 The 1995 gross income data cover in fact the period running from september 1994 to august 1995. The net incomes used in this paper however refer to the weekly income at the date of interview multiplied by 52 to arrive at annual incomes which are comparable to the net annual household incomes for the other countries.
} 
That the medium-term results are much better for the UK than the short-term also indicates that welfare state policies by the government are generally more egalitarian in the longer term. Notice the smaller gap between the short- and medium-term for the pre-government poverty rates compared to post-government rates. This suggests that it is certainly not the market that evens out inequalities over time but particularly the operation of the welfare state through income transfer policies. The downsizing of poverty in the longer run appears due to the success of the market-government nexus. Notwithstanding, the success of the UK government to reduce short and medium-term poverty, notice the higher levels of pre- and post-government poverty in the UK in the short and in the medium term as well. Particularly the high pre-government poverty figures indicate the widespread dependency on government support for low incomes.

Table 2: Pre- and post-government poverty and welfare state redistribution (percentages): short-, medium- and long-term

\begin{tabular}{|c|c|c|c|c|c|c|c|c|c|}
\hline & \multicolumn{3}{|c|}{ The Netherlands } & \multicolumn{3}{|c|}{ Germany } & \multicolumn{3}{|c|}{$\overline{\mathbf{U K}}$} \\
\hline & Pre & Post & $\begin{array}{c}\text { Redis- } \\
\text { tribu- } \\
\text { tion }\end{array}$ & Pre & Post & $\begin{array}{c}\text { Redis- } \\
\text { tribu- } \\
\text { tion }\end{array}$ & Pre & Post & $\begin{array}{c}\text { Redis- } \\
\text { tribu- } \\
\text { tion }\end{array}$ \\
\hline \multicolumn{10}{|l|}{ Short-term } \\
\hline 1987 & 26.4 & 6.4 & 78 & 29.2 & 7.0 & 76 & - & - & - \\
\hline 1993 & 27.9 & 9.8 & 65 & 32.3 & 9.2 & 72 & 39.7 & 12.0 & 70 \\
\hline \multicolumn{10}{|l|}{ Medium-term } \\
\hline $1985-89$ & 25.0 & 3.7 & 85 & 26.6 & 4.0 & 85 & - & - & - \\
\hline $1990(1)-94(5)^{\mathrm{a}}$ & 26.9 & 4.8 & 82 & 28.7 & 4.8 & 83 & 37.3 & 6.7 & 82 \\
\hline \multicolumn{10}{|l|}{ Long-term } \\
\hline $1985-94$ & 25.6 & 2.4 & 91 & 23.9 & 2.6 & 89 & - & - & - \\
\hline
\end{tabular}

a: data for 1990-1994 for the Netherlands and 1991-1995 for the UK and Germany

Source: SEP (1985-1995), GSOEP (1986-1996) and BHPS (1991-1995)

\subsection{Income inequality}

A sort of similar story can be told if the focus shifts from poverty to income inequality measures where again the idea is to look at the difference between the short-, medium- and long-term results for the three countries. The measures applied here are the 80/20 and 90/10 decile ratios of equivalent pre- and post-government income and the Gini inequality measure ${ }^{3}$.

\footnotetext{
${ }^{3}$ For a population $n$ with an income distribution vector $y\left(y_{1} \leq y_{2} \leq \ldots \leq y_{n}\right)$, the Gini $(G)$ coefficient is defined as follows: $G(y, n)=\frac{1}{2 n^{2} \mu} \sum_{i=1}^{n} \sum_{j=1}^{n}\left|y_{i}-y_{j}\right|$; where $n$ is the number of income recipients, $y_{i}$ the adult equivalent income of the $i$ th recipient $(i=1, \ldots n)$ and $\boldsymbol{\mu}$ the average income.
} 
The picture of inequality for the three countries is more or less identical to the one for poverty (

Table 3). The picture changed a bit since for the first five-year period the German government did a better job than the Dutch one to reduce inequality. In the early 1990s both countries performed equally well in reducing inequality at least for the medium-term but in the long-term the Dutch government still does a better job than the German one. In general the differences are small between the countries. Looking at the UK, though still the country with the highest post-government inequality, it now even performs better in reducing inequality for the medium term compared to the Netherlands and Germany. Again, take notice of the high level of pre-government inequality in the UK, which suggests that in the counterfactual when the government does not intervene, market operation would lead to high inequalities in labour and investment incomes. For all the three countries the mediumterm and long-term inequality is, as expected, lower than the short-term one. If a better look is taken at the long-term results, for the ten-year period 1985/6-1995/6, the outcomes for Germany and the Netherlands appear very similar in terms of pre- and post-transfer inequality according to the 80/20 equivalent income decile ratio. Note that the short-term pre-government decile ratios in Germany are rather high. When public transfers would be withdrawn from post-government income, in the counterfactual it likely will have a substantial negative income effect. This holds especially for the elderly since their earning income is likely rather low. One possible reason for this is also the design of the German pension system. The German pension system relies more on the first pillar, the basic pension while supplementary pension income from the second and third pillar is more substantial in the Netherlands and the UK.

It appears that the differences across the countries are larger for the 90/10 ratio than for the 80/20 ratio. The UK has clearly more inequality than Germany and the Netherlands, in the short-term but also in the medium-term. The reason for this is likely the larger share of very low incomes in the UK compared to Germany and the Netherlands. This might reflect a lower level of the safety net in the UK for people dependent on a minimum labour income or a social assistance benefit. 
Table 3: Decile ratios (80/20 and 90/10) of equivalent pre- and post-government income and welfare state redistribution (in per cent) in the Netherlands, Germany and the $\mathbf{U K}^{*}$

\begin{tabular}{|c|c|c|c|c|c|c|c|c|c|}
\hline \multirow{2}{*}{$\begin{array}{l}\text { 80/20 Decile } \\
\text { Ratio }\end{array}$} & \multicolumn{3}{|c|}{ Netherlands } & \multicolumn{3}{|c|}{ Germany } & \multicolumn{3}{|c|}{ UK } \\
\hline & Pre & Post & Redist. & Pre & Post & Redist. & Pre & Post & Redist. \\
\hline \multicolumn{10}{|l|}{ Short-term } \\
\hline 1987 & 5.0 & 2.0 & $60 \%$ & 11.4 & 2.0 & $82 \%$ & - & - & - \\
\hline $\begin{array}{l}1993 \\
(90 / 10)\end{array}$ & 6.8 & $\begin{array}{c}2.2 \\
(3.1)\end{array}$ & $68 \%$ & 20.1 & $\begin{array}{c}2.1 \\
(3.5)\end{array}$ & $90 \%$ & 10.1 & $\begin{array}{r}2.8 \\
(4.2)\end{array}$ & $73 \%^{\mathrm{a}}$ \\
\hline \multicolumn{10}{|l|}{ Medium-term } \\
\hline $\begin{array}{l}1985-89 \\
\text { (90/10 ratio) }\end{array}$ & 3.4 & $\begin{array}{c}1.8 \\
(2.4)\end{array}$ & $48 \%$ & 4.8 & $\begin{array}{c}1.9 \\
(2.6)\end{array}$ & $60 \%$ & - & - & - \\
\hline $\begin{array}{l}1990(1)-94(5)^{b} \\
(90 / 10 \text { ratio) }\end{array}$ & 4.9 & $\begin{array}{l}2.0 \\
(2.7)\end{array}$ & $59 \%$ & 5.0 & $\begin{array}{r}1.9 \\
(3.0)\end{array}$ & $61 \%$ & 17.0 & $\begin{array}{r}2.4 \\
(4.8)\end{array}$ & $86 \%$ \\
\hline \multicolumn{10}{|l|}{ Long-term } \\
\hline $\begin{array}{l}1985-94 \\
\text { (90/10 ratio) }\end{array}$ & 4.1 & $\begin{array}{l}1.8 \\
(2.4)\end{array}$ & $56 \%$ & 3.2 & $\begin{array}{l}1.8 \\
(2.5)\end{array}$ & $44 \%$ & - & - & - \\
\hline
\end{tabular}

* Negative and zero incomes are put to 1

a: For the UK in 1993 the second decile consists of pre-transfer incomes close to zero for which reason the 80/20 ratio appeared extremely high. Since the incomes at the lower and top end of the distribution are generally less reliable we believed that more reliable estimates could be obtained by calculating the 90/30 decile-ratio for that particular year.

b: data for 1990-1994 for the Netherlands and 1991-1995 for the UK and Germany

Source: SEP (1985-1995), GSOEP (1986-1996) and BHPS (1991-1995)

In Table 4 evidence is presented on the Gini coefficient, a widely used and well-known measure of income inequality. Again, results are presented for pre- and post-government figures to examine the presumed egalitarian effect of public transfers for the short-, medium- and long-term. The results confirm the earlier findings. Particularly pregovernment income inequality is highest in the UK whereas post-government inequality is more or less equal to the other two countries. The public transfer system in the UK is therefore as egalitarian as the transfer systems in the Netherlands and Germany. Comparing the latter two countries it appears that pre-government inequality is slightly higher in Germany whereas post-government inequality is about the same for Germany compared to the Netherlands. For that reason redistribution by public transfers is a bit higher in Germany compared to the Netherlands particularly for the short-term. For the long-term Germany and the Netherlands look very similar with respect to the egalitarian effect of public transfers. 
Table 4: Gini coefficient equivalent income and redistributive effect (in per cent) for the Netherlands, Germany and the UK

\begin{tabular}{|c|c|c|c|c|c|c|c|c|c|}
\hline & \multicolumn{3}{|c|}{ Netherlands } & \multicolumn{3}{|c|}{ Germany } & \multicolumn{3}{|c|}{$\overline{\mathbf{U K}}$} \\
\hline & Pre & Post & Redist. & Pre & Post & Redist. & Pre & Post & Redist. \\
\hline \multicolumn{10}{|l|}{ Short-term } \\
\hline 1987 & .403 & .275 & 32 & .424 & .256 & 40 & - & - & - \\
\hline 1993 & .431 & .311 & 28 & .449 & .275 & 39 & .515 & .313 & 39 \\
\hline \multicolumn{10}{|l|}{ Medium-term } \\
\hline $1985-89$ & .349 & .220 & 37 & .384 & .221 & 42 & - & - & - \\
\hline $1990(1)-94(5)^{\mathrm{a}}$ & .390 & .250 & 36 & .406 & .242 & 40 & .479 & .280 & 42 \\
\hline \multicolumn{10}{|l|}{ Long-term } \\
\hline $1985-94$ & .352 & .211 & 40 & .357 & .209 & 41 & - & - & - \\
\hline
\end{tabular}

\subsection{Recurrence of poverty}

As was illustrated earlier, apart from the length of the time period the definition of longitudinal poverty should account for the prevalence of poverty in society, i.e. the number of people at least once poor in the accounting period. First, some results are given on recurrent poverty based on the poverty hit rate, the frequency of poverty hits in the accounting period.

The post-government poverty figures for the five-year period 1991-1995 reveal that for the Netherlands and Germany about one in five people are prone to fall in poverty at least once. Hence, more than 80 per cent of all the people in these countries is never poor. In the UK, almost one in three persons experience poverty at least once in the early 1990s. If the accounting period is twice as long, ten years, one in four person in the Netherlands experience at least a single poverty spell. The prevalence of poverty is therefore much higher than the annual 'snapshots' of poverty show. The risk of falling into poverty seems quite widespread among the population. In the medium-term, more people in the UK are frequently hit by poverty than in Germany and the Netherlands. Poverty persistence seems to be only slightly higher in the UK indicating again that in the medium term the government does not do a bad job in preventing poverty. The pre-government figures show the market to be more inegalitarian in the UK for the medium term compared to the other two countries.

The German and Dutch figures for the shorter as well as for the longer accounting period look very similar. Comparison of the pre- and post-government figures show that 
particularly for the Netherlands and Germany the system of public transfers leads to a large reduction of the prevalence of poverty in society but not in all instances.

Table 5: Recurrence of poverty (poverty hit rates, in per cent) in the Netherlands, Germany and the UK

\begin{tabular}{|c|c|c|c|c|c|c|}
\hline \multirow[t]{2}{*}{ Poverty hit rate } & \multicolumn{2}{|c|}{ The Netherlands } & \multicolumn{2}{|c|}{ Germany } & \multicolumn{2}{|c|}{ UK } \\
\hline & Pre & Post & Pre & Post & Pre & Post \\
\hline \multicolumn{7}{|l|}{ 1985-1989 } \\
\hline Never & 58 & 84 & 60 & 86 & - & - \\
\hline Once & 11 & 10 & 8 & 7 & - & - \\
\hline $2 x$ & 5 & 2 & 5 & 3 & - & - \\
\hline $3 x$ & 5 & 2 & 3 & 2 & - & - \\
\hline $4 \mathrm{x}$ & 7 & 1 & 4 & 2 & - & - \\
\hline $5 x$ & 14 & 1 & 20 & 1 & - & - \\
\hline \multicolumn{7}{|l|}{$1990(1)-1994(5)^{\mathrm{a}}$} \\
\hline Never & 61 & 82 & 56 & 82 & 46 & 72 \\
\hline Once & 8 & 10 & 9 & 8 & 9 & 13 \\
\hline $2 x$ & 4 & 3 & 6 & 4 & 6 & 7 \\
\hline $3 x$ & 4 & 2 & 5 & 3 & 5 & 4 \\
\hline $4 x$ & 5 & 1 & 5 & 1 & 6 & 3 \\
\hline $5 x$ & 19 & 2 & 20 & 1 & 27 & 2 \\
\hline \multicolumn{7}{|l|}{ 1985-1994 } \\
\hline Never & 50 & 75 & 51 & 79 & - & - \\
\hline Once & 9 & 13 & 10 & 10 & - & - \\
\hline $2 x$ & 5 & 5 & 6 & 3 & - & - \\
\hline $3 x$ & 4 & 3 & 4 & 2 & - & - \\
\hline $4 x$ & 3 & 1 & 3 & 2 & - & - \\
\hline $5 x$ & 4 & 1 & 3 & 1 & - & - \\
\hline $6 x$ & 4 & 1 & 3 & 1 & - & - \\
\hline $7 x$ & 2 & 0 & 2 & 1 & - & - \\
\hline $8 x$ & 3 & 0 & 3 & 1 & - & - \\
\hline $9 x$ & 5 & 1 & 3 & 0 & - & - \\
\hline $10 x$ & 12 & 1 & 14 & 1 & - & - \\
\hline
\end{tabular}

The Dutch and UK social security system look like they make more people single year poor than would have been the case if there were no government transfers and people had to live 
from their pre-government or market income. But as was concluded elsewhere, far from being bad news this is actually good news since these people would have been poor two years or more if there were no government transfers (cf. Headey et al., 1997). Particularly in the UK the number of pre-government persistently poor, being poor for the whole 5-year period, is very high, i.e. $27 \%$.

Considering the effect of transfer systems some interesting results are found. For the UK the downsizing effect of public transfers on longitudinal poverty is particularly significant for the persistent poor and less so for the transient poor. This could signal the role of targeting of public income transfers to the 'deserving' (persistent) poor which is a typical feature of 'Atlantic' social security systems.

In all three countries the evidence suggests that the recurrence of poverty is less of a problem than persistent poverty. The majority of the people is never poor, a significant proportion is once poor but the number of people being frequently poor in a given time period is rather limited except for the UK. A better picture can be obtained if poverty profiles are taken into consideration.

\subsection{Poverty profiles}

From the previous table, it turns out that many people never experience poverty whereas others experience quite long stays in poverty. Some have a single experience of poverty during their lifetime and others move into poverty at regular occasions but only for a very short period of time. A better view on the distribution of poverty over time can be obtained by poverty profiles. A poverty profile permits to make a distinction between the never poor, the single year or transient poor, the multiple year poor or the recurrent poor (more than once poor but never longer than two years) and the persistent poor (at least three consecutive years in poverty).

These are very different for various population groups dependent on their income and money flows over time. Poverty profiles combine the information on prevalence and on duration of poverty. In Table 6 some evidence is presented. It shows how poverty is distributed across the various profile groups. The results speak for themselves and tell a similar story as before. Whereas the incidence of poverty at an annual basis was found to be highest in the UK, the data also show the higher prevalence of transient, recurrent and persistent poverty in the UK compared to the other countries. In the UK 40 per cent more people are persistent poor than in the Netherlands and Germany. Also the number of transient poor is 40 per cent higher in the UK. The number of recurrent poor is more than twice as high in the UK as in the Netherlands. 
Table 6: Post-government poverty profiles (in per cent) for the Netherlands, Germany and the UK 1990(1)-1994(5) ${ }^{a}$

\begin{tabular}{lccc}
\hline Poverty profiles & Netherlands & Germany & UK \\
\hline Never poor & 81.9 & 82.4 & 71.7 \\
Transient poor & 9.7 & 8.4 & 13.4 \\
Recurrent poor & 4.4 & 5.4 & 9.5 \\
Persistent poor & 4.0 & 3.8 & 5.5 \\
\hline a: data for 1990-1994 for the Netherlands and 1991-1995 for the UK and Germany & \\
Source: SEP (1991-1995), GSOEP (1992-1996) and BHPS (1991-1995)
\end{tabular}

Though the extent of transient poverty is lower in Germany than in the Netherlands, the percentage recurrent poor is higher. No significant difference is found in terms of persistent poverty between the two countries.

\subsection{Poverty spells}

From the findings presented earlier it might be concluded that the longitudinal poverty concept is multifaceted and complex. For a good understanding it is required to distinguish between the various forms of longitudinal poverty as they become manifest over time. The poverty hit rates just count the number of times people are poor within the accounting period and therefore say little about the duration of poverty. The poverty profiles combine the information on prevalence and on duration i.e. the length of the poverty spell but still bear a methodological weakness. It mistakenly does not correct for the impact of left and right censoring. Even when people are poor for all of the years for which the data give the information, it is not known exactly how long the spell has lasted since the beginning nor the ending of the spell is known (left and right censoring).

In the next analysis (see Table 7), left censored spells, for which the starting date is unknown, are excluded from the analysis but right censored spells are included. Contrary to what might be expected beforehand, the distribution of pre-government spell is very similar in the three countries. The pre-government evidence shows that in the counterfactual of no government intervention, the market would produce similar levels of poverty persistency across countries. Nevertheless, pre-government poverty spells tend to last long in both countries indicating that the market does a poor job in terms of preventing persistent poverty. Government interventions are needed to shorten spells of poverty. Postgovernment poverty spells therefore, appear to be much shorter. After three years about 20 per cent of the people who started a spell three years earlier are still poor and were not capable of escaping from poverty. The post-government survival rates for the UK are slightly higher than for the Dutch and German situation. These outcomes do not support the hypothesis that there is a strong efficiency-equity trade-off. 
Table 7: Duration of poverty spells: Cumulative staying probability (in per cent) for the Netherlands, Germany and the UK

\begin{tabular}{lllllll}
\hline Cum. Staying & \multicolumn{2}{c}{ The Netherlands } & \multicolumn{2}{c}{ Germany } & \multicolumn{3}{c}{ UK } \\
probability & Pre & Post & Pre & Post & Pre & Post \\
\hline 1985-1989 & 63 & 43 & 66 & 49 & - & - \\
After 1 year & 56 & 30 & 53 & 38 & - & - \\
After 2 years & 53 & 24 & 50 & 24 & - & - \\
After 3 years & & & & & & \\
1990(1)-1994(5) & & & & & & \\
After 1 year & 65 & 40 & 69 & 48 & 69 & 47 \\
After 2 years & 55 & 23 & 58 & 30 & 57 & 29 \\
After 3 years & 50 & 22 & 51 & 20 & 50 & 23 \\
1985-1994 & & & & & & \\
After 1 year & 55 & 32 & 66 & 45 & - & - \\
After 2 years & 46 & 20 & 54 & 31 & - & - \\
After 3 years & 39 & 15 & 48 & 20 & - & - \\
After 4 years & 35 & 12 & 43 & 12 & - & - \\
After 5 years & 32 & 11 & 37 & 7 & - & - \\
After 6 years & 29 & 10 & 35 & 7 & - & - \\
After 7 years & 29 & 10 & 33 & 5 & - & - \\
After 8 years & 29 & 10 & 32 & 5 & - & - \\
\hline a: data for 1990-1994 for the Netherlands and 1991-1995 for the UK and Germany & & \\
Source: SEP (1985-1995), GSOEP (1986-1996) and BHPS (1991-1995) & & \\
& & & & & & \\
\end{tabular}

Most spells end within the first and second year after they began. After the second year, the likelihood of escaping poverty diminishes rapidly. The results for the five year period should be taken with caution because of the limited time span. However, if a longer observation period of ten years is taken, the results do not change much. In the longer run, most poverty spells also tend to end within the first three years after a spell beginning. If spells last longer than three years, the likelihood of escaping from poverty is extremely low.

Pre-government spells in Germany last a bit longer than in the Netherlands. This is also the case for post-government poverty spells. Note, however, that after six years in the Netherlands nobody seems to be able to escape from poverty anymore, whereas in Germany still a small portion of the people is capable of doing that. 


\section{A MODE L BASE D ME ASURE OF PERSISTENT POVERTY}

The fourth and last dimension of longitudinal poverty that is discussed here is the stability of income positions over time. The data presented previously also provided information on the stability of individual income positions. These individual data suggest that income volatility is relatively high. Another way to assess the stability of income positions over time is by applying a model-based and therewith population wide measure of income stability over time. The idea behind this model is that what really matters for people in the long run is their permanent income. The basic assumption is that people have a kind of latent long-term income-to-needs level from which occasional departures are possible due to temporary income shortfalls or income surpluses associated with the occurrence of various sorts of events, such as (un)employment, disability or illness, overtime work or working time reductions. In a separate paper (Fouarge et al., 2000) a model-based measure of persistent poverty has been estimated that follows the methodology that Lillard and Willis (1978) applied on earnings mobility data. The model has been applied for the estimation of permanent income-to-needs ratios and persistent poverty (Duncan and Rodgers, 1991). The model can be estimated with or without explanatory variables. In the first case when appropriate variables are added to it, the model could also be used to monitor changes in permanent income-to-needs positions due to the occurrence of certain life events such as loosing a job, work-time reduction, marital dissolution or early retirement. Here, the results are presented of a model without covariates (model I) and a model with inclusion of household formation variables (model II). ${ }^{4}$

The estimates for the seven year period 1988(9)-1994(5) show that the extent of persistent poverty in the Netherlands and Germany is about the same, 2.0 and 1.6 per cent (Table 8). For the UK persistent poverty is highest among the three countries, 5.5 per cent. These results confirm the findings presented earlier for the individual measures of income volatility and stability over time across the three countries.

Viewing the results for model II with inclusion of household formation variable, it appears that lone-parents are clearly worst off. The persistent poverty rate for lone-parent households is much larger than for the other household types. Persistent poverty among single elderly women is larger than average in all countries, but more so in the UK.

4 Here, we briefly present the results of the estimations conducted in another paper (Fouarge \& Muffels 2000) using seven year of panel data for all three countries. For more details about the model specification and the estimation procedure, the reader is refered to that paper. 
Table 8: Persistent poverty estimates (in per cent) for the Netherlands, Germany and the UK. Results of fixed effect panel regression models

\begin{tabular}{lccc}
\hline & $\begin{array}{c}\text { The Netherlands } \\
(1988-1994)\end{array}$ & $\begin{array}{c}\text { Germany } \\
(1989-1995)\end{array}$ & $\begin{array}{c}\text { UK } \\
(1991-1997)\end{array}$ \\
\hline $\begin{array}{l}\text { Model I. Proportion in persistent } \\
\text { poverty (\%) (model }\end{array}$ without & 2.0 & 1.6 & 5.5 \\
covariates) & & & \\
Model II. Proportion in persistent & & & \\
poverty (\%) (model with covariates) & & & \\
- Single elderly man & 2.5 & 0.8 & 11.0 \\
- Single elderly woman & 4.8 & 6.1 & 24.8 \\
- Couple, male head, children & 2.3 & 1.3 & 3.7 \\
- Couple, female head, children & 11.0 & 2.4 & 4.8 \\
- Lone parent & 22.2 & 29.5 & 38.6 \\
\hline
\end{tabular}

a: data for 1988-1994 for the Netherlands and 1989-1995 for Germany and 1991-1997 for the UK Source: SEP (1989-1995), GSOEP (1990-1996) and BHPS (1991-1997)

Perhaps more surprising is the high rate of persistent poverty for female headed households with children in the Netherlands compared to the other two countries. Obviously, they have few chances to escape from poverty through household formation events ([re]marriage) or labour market events (acquiring a long-hours paid job) and therefore are deemed to stay into poverty until children has grown up. The evidence indeed shows that remarriage rates in the Netherlands are rather low as are the opportunities to childcare relief.

\section{POVERTY PROFILES AND THEIR DETERMINANTS}

The analyses so far have given a brief description of the achievements of various sorts of welfare states as they currently exist in the three countries with respect to the reduction of short and long term poverty and inequality. The picture of the performance of the welfare states changes when we move on from the conventional static to the dynamic approaches of poverty and inequality. The conclusion was that over time twice as many people are prone to fall into poverty at regular occasions in the observation period compared to the conventional annual snap-shots. The economic mobility in the three countries, but particularly in Germany and the Netherlands, is higher than expected. According to neo-classical theory these matured and fairly generous welfare states might cause disincentive effects that 
negatively affect mobility rates. Most people, when they fall into poverty, seem capable of moving out rather quickly through labour market changes, changes in household formation events or household budget strategies.

Recurrent poverty appears less of a problem for the three welfare states than persistent poverty although the number of people in recurrent poverty, particularly in the UK, is quite high. This reasoning holds only when recurrent poverty is not a prestate or entrance gate to persistent poverty. In this part this issue will be examined in more detail. The question is particularly to what extent the persistent poor are different from the transient and recurrent poor. Persistent poverty appears rather modest in the long-term, but rather substantial in the medium term. But even if persistent poverty is on average low it should be of concern for policy makers since the likelihood of extended stays in poor living conditions rapidly rises with increasing spell length and might create social and social-psychological problems at the personal level. Persistent poverty is also of concern since it is very unevenly spread across the population and hits particular vulnerable groups in society. In this section the determinants of the different poverty profiles are examined. Particularly interest exists in the events that trigger the belonging to different poverty profiles or poverty "careers".

Multinomial logit models ${ }^{5}$ are estimated for the likelihood of belonging to each of the longitudinal poverty profiles, being never poor, transient, recurrent or persistent poor. In the model, four types of variables are included which are likely important factors that trigger the existence of these different profiles:

- $\quad$ Personal and household characteristics such as age, sex, marital status, household composition, number of children, divorced, widowed;

- Socio-economic characteristics like education level, labour market status or socio-economic status (disabled, retired, social assistance);

- $\quad$ Household formation events during the observation period (marriage, divorce or separation);

- $\quad$ Labour market events (find work, lost work, increase in number of workers in the household, decrease in working members, more working hours, less working hours).

The multinomial model that is estimated distinguishes four poverty states (never poor, transient poor, recurrent poor and persistent poor) where the 'never poor' act as the reference group. The probability of being in either state as compared to the 'reference state' is given by the following equation:

${ }^{5}$ Models are estimated in ST AT A version 6.0. 
$P(y=j)=\frac{\exp \left(\sum_{k=1}^{K} \beta_{j k} x_{k}\right)}{1+\sum_{j=1}^{J-1} \exp \left(\sum_{k=1}^{K} \beta_{j k} x_{k}\right)}$

with $\mathrm{J}=4$ (so $\mathrm{j}=0,1,2,3$ ), $\mathrm{j}=0$ being the reference state and $\mathrm{K}$ the number of explanatory variables. These probabilities are computed for each individual on the basis of all relevant characteristics.

The results are given in Table 9, Table 10 and Table 11 for the Netherlands, Germany and the UK, respectively. The results for all of the three countries look plausible. The fit of the estimated models is very good. Let us first look at the results for belonging to the persistent poor compared to being never poor during the five-year observation period (1991-1995).

For the Netherlands it is found that the young heads of households are much more prone to poverty persistence than the elder heads. Male heads of households are less likely persistent poor than female heads. Note also the very strong impact of the number of children on the likelihood of persistent poverty. If the impact of household formation events is looked at, it is clear that separation during the observation period strongly increases the likelihood of poverty persistency. Though separated (widowed or divorced) heads at the beginning of the spell have higher chances to become persistent poor, lone parents are less likely persistent poor compared to unmarried singles. It is clear that widowhood and divorce raises the likelihood of poverty persistence, but the care for children raises the necessity to earn additional income to cover the additional costs for child-care. Married heads running into poverty have less chances to escape from poverty than single persons probably because of lack of labour market opportunities. Labour market related variables appear to exert even a stronger impact on persistent poverty. The more people work in the household the less likely the household falls into poverty. For the same reason households where the head is unemployed at the beginning of the poverty spell are more likely persistent poor. If the head or a household member looses its job the likelihood of persistent poverty increases strongly and the reverse holds if they get into work. Given the impact of labour market events on the likelihood of becoming persistent poor it is interesting to look at the impact of human capital variables. A low educational level has a positive impact on poverty persistence. Education, even at the lower layers of the labour market, pays in terms of preventing people from persistent poverty.

The results for the other countries are more or less similar. For the UK and Germany it is found that households with a separated head are more likely persistent poor. The larger the number of children the more likely the household becomes persistent poor. Elder heads are similarly to the Netherlands less likely persistent poor although for household 
members the likelihood of escaping from poverty falls with increasing age. For Germany and the Netherlands separation during the time of the spell has again a strong impact on the likelihood of being persistent poor.

The effects for the labour market variables and labour market events are similar to the effects found for the Netherlands. The more workers there are in the household the less likely the household members are persistent poor. Loosing a job during the observation period by either the head or the household member raises the probability of becoming persistent poor. However, in Germany, the variable 'finding work' at the individual level has a positive effect on the likelihood of being persistent poor. This effect could be attributed to the role of marginal or precarious jobs (flexible, temporary jobs) which offer little opportunities, given their low pay, to escape from poverty. A high educational level decreases the likelihood of being persistent poor in Germany but not in the UK. However, as in the Netherlands, and unlike Germany, a lower educational level raises the probability of being persistent poor in the UK.

\section{To what extent are the persistent poor different from the recurrent and transient poor?}

The evidence in this paper suggests that the sorts of variables that explain the belonging to the transient, recurrent or persistent poor are the same for all of the various categories. The magnitude of the effects, however, is larger for the persistent poor than for the recurrent poor, and the effects for the recurrent poor are stronger than for the transient poor. The persistent poor are more prone to belonging to a household with a separated head or where separation occurs during the spell and by a lower equivalent net household income, a lower education level, less annual working hours, a higher age of the household head and higher unemployment and disability. The recurrent poor are a bit less old, less often unemployed, more of them have a job and their average earnings are higher. The transient poor are on their turn doing a bit better than the recurrent poor in terms of the impact these variables have on poverty persistence. The belonging to either one group seems particularly affected by human capital characteristics and caring obligations. The weaker the association with the labour market is -because of obsolete skills, low qualifications, or a low human capital because of age or caring duties- the higher the likelihood of being persistent poor. In the Netherlands and the UK about $80 \%$ of the persistent poor are unemployed. More than $60 \%$ of the recurrent poor and less than $50 \%$ of the transient poor are unemployed. In Germany these figures are 53\%, 50\% and 34\% for, respectively, the persistent, the recurrent and the transient poor. 
Table 9: A multinomial logit model for being in either of the four poverty states: never poor, transient poor, recurrent poor or persistent poor, 1990-1994 for the Netherlands

\begin{tabular}{|c|c|c|c|c|c|c|}
\hline \multirow{3}{*}{$\begin{array}{l}\text { Reference state: } \\
\text { never poor }\end{array}$} & \multicolumn{2}{|c|}{ Transient poor } & \multicolumn{2}{|c|}{ Recurrent poor } & \multicolumn{2}{|c|}{ Persistent poor } \\
\hline & Coef. & $\mathbf{Z}$ & Coef. & $\mathbf{Z}$ & Coef. & $\mathbf{Z}$ \\
\hline & \multicolumn{6}{|c|}{$N=6,557 ;$ LR Chisq=2,083; Log likelih.=-2,624; Pseudo Rsq=0.284 } \\
\hline \multicolumn{7}{|c|}{ a. Personal and household characteristics } \\
\hline Elderly & -0.344 & -1.053 & -0.825 & -1.400 & -1.259 & -1.504 \\
\hline Elder head & 0.357 & 1.106 & -0.937 & -1.703 & -0.914 & -1.274 \\
\hline Young & 0.195 & 1.187 & 0.499 & 1.925 & -0.145 & -0.414 \\
\hline Young head & $0.819 *$ & 2.892 & 0.107 & 0.241 & $2.944^{*}$ & 5.060 \\
\hline Male & -0.004 & -0.038 & -0.069 & -0.425 & -0.020 & -0.094 \\
\hline Male head & -0.305 & -1.299 & 0.600 & 1.791 & $-1.533 *$ & -2.461 \\
\hline Number of children & 0.056 & 1.030 & 0.051 & 0.607 & $0.396^{*}$ & 3.850 \\
\hline Married head & -0.037 & -0.169 & -0.397 & -1.315 & $2.616^{*}$ & 3.534 \\
\hline Separated head & 0.236 & 1.007 & 0.300 & 0.919 & $1.567^{*}$ & 2.678 \\
\hline Lone parent & 0.218 & 0.747 & -0.166 & -0.416 & $-1.364 *$ & -2.536 \\
\hline \multicolumn{7}{|c|}{ b. Socio-economic characteristics } \\
\hline $\begin{array}{l}\text { Household } \\
\text { income/1000 }\end{array}$ & $-0.128 *$ & -16.615 & $-0.187 *$ & -16.821 & $-0.187 *$ & -13.960 \\
\hline Lower educated head & 0.140 & 1.077 & 0.054 & 0.288 & 0.410 & 1.781 \\
\hline Higher educated head & $0.617 *$ & 4.621 & 0.399 & 1.706 & 0.197 & 0.498 \\
\hline Number of employed & $-0.277 *$ & -2.652 & $-0.987 *$ & -4.661 & -0.127 & -0.566 \\
\hline Employed & 0.063 & 0.583 & $0.077 *$ & 0.503 & $-0.373^{*}$ & -1.961 \\
\hline Head not employed & 0.382 & 1.889 & 1.196 & 3.734 & $4.578^{*}$ & 8.737 \\
\hline \multicolumn{7}{|c|}{ c. Household formation events during spell } \\
\hline Head married & -0.073 & -0.220 & -0.258 & -0.449 & 0.123 & 0.139 \\
\hline Head separated & $1.803^{*}$ & 10.092 & $1.814^{*}$ & 6.884 & $1.167^{*}$ & 2.994 \\
\hline \multicolumn{7}{|c|}{ d. Labour market events during spell } \\
\hline Head lost work & $0.751 *$ & 3.911 & $1.447 *$ & 4.546 & $3.837^{*}$ & 7.192 \\
\hline Head found work & 0.471 & 1.807 & -0.295 & -0.882 & -0.749 & -1.781 \\
\hline Lost work & -0.060 & -0.266 & -0.219 & -0.607 & 0.146 & 0.341 \\
\hline Find work & $0.459 *$ & 2.266 & 0.137 & 0.465 & 0.362 & 0.828 \\
\hline More workers & $-0.637 *$ & -3.558 & 0.229 & 0.896 & -0.528 & -1.331 \\
\hline Less workers & $1.066^{*}$ & 6.221 & $1.613^{*}$ & 5.444 & 0.613 & 1.647 \\
\hline Constant & 0.007 & 0.022 & -0.446 & -0.870 & $-4.532 *$ & -5.551 \\
\hline
\end{tabular}


Table 10: A multinomial logit model for being in either of the four poverty states: never poor, transient poor, recurrent poor or persistent poor, 1991-1995 for Germany

\begin{tabular}{|c|c|c|c|c|c|c|}
\hline \multirow{2}{*}{$\begin{array}{l}\text { Reference state: } \\
\text { Never poor }\end{array}$} & \multicolumn{2}{|c|}{ Transient poor } & \multicolumn{2}{|c|}{ Recurrent poor } & \multicolumn{2}{|c|}{ Persistent poor } \\
\hline & Coef. & $\mathbf{Z}$ & Coef. & $\mathbf{Z}$ & Coef. & $\mathbf{Z}$ \\
\hline & \multicolumn{6}{|c|}{$N=12,492 ;$ LR Chisq=4,137; Log likelih. $=-5,686 ;$ Pseudo Rsq=0.26? } \\
\hline \multicolumn{7}{|c|}{ a. Personal and household characteristics } \\
\hline Elderly & 0.130 & 0.502 & -0.329 & -0.819 & -0.266 & -0.506 \\
\hline Elder head & $-0.793^{*}$ & -3.183 & $-1.111^{*}$ & -2.967 & $-1.172 *$ & -2.416 \\
\hline Young & $0.245^{*}$ & 2.295 & 0.203 & 1.439 & 0.190 & 1.025 \\
\hline Young head & $0.726^{*}$ & 4.109 & $0.691 *$ & 3.160 & 0.464 & 1.692 \\
\hline Male & $-0.179 *$ & -2.475 & $-0.232 *$ & -2.355 & -0.124 & -0.962 \\
\hline Male head & $0.474 *$ & 5.470 & $0.616^{*}$ & 5.212 & $0.402 *$ & 2.644 \\
\hline Number of children & $0.136^{*}$ & 3.754 & $0.272 *$ & 6.059 & $0.219^{*}$ & 3.645 \\
\hline Married head & $-0.696^{*}$ & -5.742 & $-1.122 *$ & -7.559 & $-1.039 *$ & -5.605 \\
\hline Separated head & $0.667 *$ & 4.442 & 0.078 & 0.408 & 0.094 & 0.421 \\
\hline Lone parent & $0.578^{*}$ & 3.463 & $0.332 *$ & 1.626 & $0.965^{*}$ & 4.216 \\
\hline \multicolumn{7}{|c|}{ b. Socio-economic characteristics } \\
\hline $\begin{array}{l}\text { Household } \\
\text { income/1000 }\end{array}$ & \multicolumn{5}{|c|}{ income/1000 } & -22.284 \\
\hline Lower educated head & $-0.207^{*}$ & -2.755 & $0.268 *$ & 2.754 & 0.057 & 0.447 \\
\hline Higher educated head & $-0.391 *$ & -2.663 & -0.212 & -0.948 & $-0.807 *$ & -2.222 \\
\hline Number of employed & $-0.215^{*}$ & -3.101 & $-0.716^{*}$ & -6.727 & $-0.907 *$ & -5.847 \\
\hline Employed & 0.037 & 0.310 & -0.107 & -0.639 & -0.419 & -1.764 \\
\hline Head not employed & $0.727 *$ & 5.486 & $0.406^{*}$ & 2.322 & $0.573 *$ & 2.462 \\
\hline \multicolumn{7}{|c|}{ c. Household formation events during spell } \\
\hline Head married & $-0.749 *$ & -3.728 & $-0.651 *$ & -2.556 & -0.509 & -1.591 \\
\hline Head separated & $1.419 *$ & 11.829 & $1.480 *$ & 8.846 & $1.498 *$ & 6.975 \\
\hline \multicolumn{7}{|c|}{ d. Labour market events during spell } \\
\hline Head lost work & $1.143^{*}$ & 8.943 & $1.109 *$ & 6.477 & $0.779 *$ & 3.402 \\
\hline Head found work & 0.313 & 1.642 & 0.020 & 0.076 & -0.095 & -0.285 \\
\hline Lost work & -0.042 & -0.278 & 0.125 & 0.606 & 0.257 & 0.910 \\
\hline Find work & 0.124 & 0.755 & 0.347 & 1.607 & 0.496 & 1.753 \\
\hline More workers & $-0.286^{*}$ & -2.223 & $-0.655^{*}$ & -3.655 & $-0.870^{*}$ & -3.418 \\
\hline Less workers & $0.724 *$ & 6.296 & $1.283^{*}$ & 7.898 & $2.060 *$ & 9.424 \\
\hline Constant & -0.039 & -0.200 & $1.935^{*}$ & 7.458 & $2.333^{*}$ & 6.983 \\
\hline
\end{tabular}

*: coefficient significant at the 5\% level

Source: GSOEP (1992-1996) 
Table 11: A multinomial logit model for being in either of the four poverty states: never poor, transient poor, recurrent poor or persistent poor, 1991-1995 for the UK

\begin{tabular}{|c|c|c|c|c|c|c|}
\hline \multirow{3}{*}{$\begin{array}{l}\text { Reference state: } \\
\text { Never poor }\end{array}$} & \multicolumn{2}{|c|}{ Transient poor } & \multicolumn{2}{|c|}{ Recurrent poor } & \multicolumn{2}{|c|}{ Persistent poor } \\
\hline & Coef. & $\mathbf{Z}$ & Coef. & $\mathbf{Z}$ & Coef. & $\mathbf{Z}$ \\
\hline & \multicolumn{6}{|c|}{$N=7,118 ;$ LR Chisq=3,073; Log likelih. $=-4,502 ;$ Pseudo $R s q=0.254$} \\
\hline \multicolumn{7}{|c|}{ a. Personal and household characteristics } \\
\hline Elderly & 0.222 & 0.737 & 0.201 & 0.531 & $1.120^{*}$ & 2.031 \\
\hline Elder head & -0.526 & -1.786 & $-0.932 *$ & -2.518 & $-1.442 *$ & -2.649 \\
\hline Young & 0.114 & 0.893 & $0.349 *$ & 2.145 & 0.195 & 0.954 \\
\hline Young head & 0.281 & 1.298 & 0.219 & 0.885 & -0.069 & -0.211 \\
\hline Male & 0.110 & 1.356 & -0.014 & -0.131 & 0.052 & 0.378 \\
\hline Male head & 0.091 & 0.896 & 0.036 & 0.271 & -0.270 & -1.643 \\
\hline Number of children & $0.204 *$ & 4.628 & $0.381 *$ & 7.007 & $0.592 *$ & 9.160 \\
\hline Married head & -0.223 & -1.881 & $-0.562 *$ & -3.836 & $-0.656^{*}$ & -3.617 \\
\hline Separated head & $0.829 *$ & 4.769 & 0.318 & 1.571 & $0.558^{*}$ & 2.396 \\
\hline Lone parent & -0.188 & -0.954 & -0.245 & -1.089 & $-0.563^{*}$ & -2.108 \\
\hline \multicolumn{7}{|c|}{ b. Socio-economic characteristics } \\
\hline $\begin{array}{l}\text { Household equivalent } \\
\text { income } / 1000\end{array}$ & $-0.191 *$ & -12.055 & $-0.451 *$ & -16.176 & -0.584 & -14.326 \\
\hline Lower educated head & -0.148 & -1.239 & 0.075 & 0.422 & $1.499 *$ & 3.913 \\
\hline Higher educated head & $-0.481 *$ & -3.482 & -0.036 & -0.174 & $1.452 *$ & 3.498 \\
\hline Number of employed & $-0.521 *$ & -6.147 & $-1.051 *$ & -7.809 & $-1.067 *$ & -5.644 \\
\hline Employed & -0.174 & -1.183 & -0.006 & -0.030 & 0.027 & 0.094 \\
\hline Head not employed & 0.121 & 0.763 & $0.486^{*}$ & 2.305 & $0.818^{*}$ & 3.006 \\
\hline \multicolumn{7}{|c|}{ c. Household formation events during spell } \\
\hline Head married & -0.382 & -1.657 & -0.036 & -0.131 & 0.180 & 0.574 \\
\hline Head separated & $0.499 *$ & 3.169 & $0.912 *$ & 4.855 & $1.245^{*}$ & 4.916 \\
\hline \multicolumn{7}{|c|}{ d. Labour market events during spell } \\
\hline Head lost work & $0.818^{*}$ & 5.614 & $0.757 *$ & 3.668 & 0.465 & 1.460 \\
\hline Head found work & 0.126 & 0.663 & -0.002 & -0.008 & $-0.939 *$ & -3.138 \\
\hline Lost work & 0.192 & 1.057 & $0.659 *$ & 2.589 & $0.865^{*}$ & 2.264 \\
\hline Find work & 0.204 & 1.251 & 0.246 & 1.049 & $-0.694 *$ & -2.039 \\
\hline More workers & $0.236^{*}$ & 1.967 & $-0.717 *$ & -3.790 & 0.254 & 1.230 \\
\hline Less workers & $1.051^{*}$ & 7.532 & $1.734 *$ & 8.861 & $1.454^{*}$ & 4.997 \\
\hline Constant & -0.134 & -0.550 & $0.811 *$ & 2.467 & -0.856 & -1.660 \\
\hline
\end{tabular}

*: coefficient significant at the $5 \%$ level

Source: BHPS (1991-1995) 
Time varying variables

Although these findings reveal what might be expected beforehand, the models have one important drawback: they assume that the poverty career is determined by characteristics at the beginning of the observation period. The models estimated in this paper cover a five-year period. The time between the start of the poverty spell and the beginning of the observation period is on average two and a half years. When the time horizon is longer, say ten years, then the situation of, on average, five years back is assumed to determine the occurrence of a poverty profile. This is a rather long period in which much may have changed. Although some of the variables included in the model are time invariant, most are not. For that reason, it is better to look at individual, household and labour market characteristics just before the start of a poverty profile and to assess the impact of life events occurring in the period just before the beginning up to just at the end of the poverty spell. This means that the models should take account of the timing of these variables. This constitutes the subject of current research.

\section{CONCLUSIONS}

The aim of our research is to develop longitudinal measures of poverty and inequality, to apply them on some of the longer running panel studies and to examine their usefulness for policy purposes with respect to European social policy. These measures will then in a later step be applied on the ECHP data. In this paper we applied some of these longitudinal measures of poverty and inequality on the existing longer running panel data sets for Germany, the Netherlands and the UK. The results are reported from two perspectives. First, across welfare states, the question was addressed how do welfare states perform in terms of preventing poverty and particularly poverty persistence. Next, across time, the focus was on a comparison of the short-, medium- and longer term results in terms of preventing poverty (Germany and the Netherlands for ten years, five years for all three countries) .

Across welfare states it is clear that the Dutch and German welfare states do an excellent job in preventing poverty and inequality not only in the short-term but also in the mediumand longer term without distorting efficiency to considerable extents. The UK system produces higher levels of poverty, whether transient, recurrent or persistent. The UK has $40 \%$ more recurrent and persistent poverty over a 5-year period than Germany or the Netherlands. Comparing the Dutch and German welfare systems it turns out that they are performing equally well in preventing welfare state dependency in the medium- and longer term. Compared to Germany and the Netherlands, the UK does a poorer job but mostly in the short-term. In the longer term the redistribution results become much better and similar to the ones for Germany and the Netherlands. Comparison of pre- and post-government poverty rates makes clear that the market does a much poorer job than the governments in preventing poverty in the short-, medium- and long-term. Particularly in the UK the pre- 
government poverty rates are higher in the medium than in the short-term whereas the postgovernment poverty rates are lower. The overall performance of these systems to reduce recurrent and persistent poverty and inequality appears very successful in Germany and the Netherlands, but also in the UK with a different and more liberal tradition of the set-up of the welfare system. Nevertheless the UK has to accept fairly high levels of recurrent and persistent poverty among particular group such as the single parent families and the unemployed.

Across time, it was already noticed that these governments perform better in the mediumand longer term than in the short-term. The Dutch and German welfare systems are very successful in reducing inequality and poverty, particularly in the longer term. But also the UK welfare system is successful at reducing poverty but more so in the longer run than in the short run. For all the countries, the UK included, it is not the market that can prevent the existence of long-term poverty. On the contrary, it is through government intervention that poverty is successfully tackled. Longitudinal measures of poverty give a better, deeper view on poverty and tell a different story than the usual snapshots. On the one hand, they show that poverty is not reduced to be a problem for a small group of low-income people in society. It appears a widespread social phenomenon because in the longer run many more people are prone to poverty than in the short run. On the other hand, it makes clear that much of poverty in the long-term is transient. Many people have a single experience of poverty and do not need much help to escape from poverty and to keep out of it. In general there is much more economic mobility than the annual snapshots suggest even at these low levels of income. There is another story told by these figures which is that, apart from the high levels of economic mobility among the poor within particular categories like the longterm unemployed, the disabled and the separated households, there is much persistent poverty. Income mobility and poverty persistence go hand in hand even in growing economies and matured and developed welfare states. The explanatory models as estimated in this paper, suggest that household formation and labour market events are both responsible for people falling into poverty or to escape from it. Where the transient and recurrent poor share many characteristics of the persistent poor, the likelihood of being part of a separated household, having a low education level or low earnings is in all instances larger with the persistent poor. The persistent poor share the experience of divorce and family breaks and the occurrence of significant changes in the labour market status of household members due to work loss or work gain. They have a lower human capital value on the labour market and they lack the resources in terms of skills, education and working experience that can be exchanged on the market for jobs. 


\section{REFERENCES}

Atkinson, A.B. (1987). 'On the Measurement of Poverty', Econometrica, 55 (4), 749764.

Atkinson, A.B., Rainwater, L. \& Smeeding, T.M. (1995). Income Distribution in OECD Countries, Paris: OECD.

Berghman, J. (1995). 'Social exclusion in Europe: policy context and analytical framework'. In G. Room (ed.). Beyond the threshold: the measurement and analysis of social exclusion. Bristol: The Policy Press.

Callan. T., Nolan, B., Whelan, C. \& Williams, J. (1996). Poverty in the 1990's. evidence from the 1994 living in Ireland survey. ESRI-Dublin. Oak Tree Press. Dublin.

Dirven, H-J., Fouarge, D., \& Muffels, R. (1998). 'Poverty in the Netherlands'. In: J. Dixon \& D. Macarov (eds.). Poverty: a persistent global reality. London: Routledge.

Duncan. G. \& W. Rodgers (1991). "Has children's poverty become more persistent?". American Sociological Review. 56: 538-550.

Fouarge, D. \& R. Muffels (2000). 'Model-based estimates of longitudinal poverty for the Netherlands, Germany and the UK'. Paper for the $14^{\text {th }}$ Annual Conference of the European Society for Population Economics, Bonn 15-17 june 2000.

Headey, B., Goodin, R.E., Muffels, R. \& Dirven, H-J. (1997). 'Welfare over time: three worlds of welfare capitalism in panel perspective', Journal of Public Policy, 17, 329-59.

Headey, B., R. Muffels, R. Goodin \& H.-J. Dirven (2000), Is There a Trade-Off Between Economic Efficiency and a Generous Welfare State? A Comparison of Best Cases of 'The Three Worlds of Welfare Capitalism'. Journal of Social Indicators Research, Vol. 50, 2, pp. 115-157

Jarvis, S. and Jenkins, S.P. (1998). Derived Net Income Variables for BHPS Waves 1-6. Economic and Social Research Council, Research Centre on Micro-Social Change, University of Essex: The Data Archive, Colchester.

Kakwani, N. (1986). Analysing Redistribution Policies. Cambridge: Cambridge University Press.

Lillard. L \& R. Willis (1978). "Dynamic aspects of earnings mobility". Econometrica. 46 (5): $985-1012$.

Mitchell, D. (1991). Income Transfers in Ten Welfare States. Aldershot: Avebury.

Muffels, R.JA. (1993). Welfare Economic Effects of Social Security. Essays on Poverty, Social Security and Labor Markets: Evidence from Panel Data.. Series on Social Security Studies, Report No. 21. Tilburg, Netherlands: Tilburg University.

Ringen, S. (1988). 'Direct and Indirect Measures of Poverty', Journal of Social Policy, 17 (3), 351-365.

Sen, A. (1979). 'Issues in the Measurement of Poverty', Scandinavian Journal of Economics, 81, 285-307.

Smeeding, T.M., Saunders, P., Coder, J., Jenkins, S., Fritzell, J., Hagenaars, A.J.M. \& Wolfson, M. (1993). 'Poverty, inequality and family living standards across seven nations: the effect of non-cash subsidies for health, education and housing'. Review of Income and Wealth , 39, 229-56.

Walker, R. (1994). Poverty Dynamics: Issues and Examples. Avebury, Aldershot, ISBN 1

85628929 X. 


\section{OSA-Working papers}

No.

WP2000-1

Jan Boone \& Jan C. van Ours

WP2000-2 Michèle Belot \& Jan C. van Ours

WP2000-3 Jan Boone \& Lans Bovenberg

WP2000-4 Didier Fouarge \& Ruud Muffels

WP2000-5 Patrick Francois and Jan C. van Ours

WP2000-6 Ruud Muffels, Didier Fouarge \& Ronald Dekker
Title

Modeling financial incentives to get unemployed back to work

Does the recent success of some OECD countries in lowering their unemployment rates lie in the clever design of their labour market reforms?

Optimal labour taxation and search

Persistent poverty in the Netherlands, Germany and the UK

A model-based approach using panel data for the 1990s*

Gender Wage Differentials in a Comparative Labour Market: The household Interaction Effect.

Longitudinal poverty and income inequality A comparative panel study for the Netherlands, Germany and the UK. 